\title{
A two-arm, randomized, controlled, multi-centric, open-label Phase-2 study to evaluate the efficacy and safety of Itolizumab in moderate to severe ARDS patients due to COVID-19
}

Suresh Kumar, ${ }^{1}$ Rosemarie de Souza, ${ }^{2}$ Milind Nadkar, ${ }^{3}$ Randeep Guleria, ${ }^{4}$ Anjan Trikha, ${ }^{4}$ Shashank R. Joshi, ${ }^{5}$ Subramanian Loganathan, ${ }^{6 *}$ Sivakumar Vaidyanathan, ${ }^{6}$ Ashwani Marwah, ${ }^{6}$ Sandeep N. Athalye ${ }^{6}$

${ }^{1}$ MAMC medical college and Lok Nayak Jai Prakash Narayan Hospital, New Delhi, Delhi, India;

${ }^{2}$ Topiwala National Medical College \& B. Y. L. Nair Charitable Hospital, Mumbai, Maharashtra, India;

${ }^{3}$ Seth GS medical college and KEM Hospital, Mumbai, Maharashtra, India;

${ }^{4}$ All India Institute of Medical Sciences, New Delhi, Delhi, India;

${ }^{5}$ Indian College of Physicians and Lilavati Hospital, Mumbai, Maharashtra, India

${ }^{6}$ Biocon Biologics Indian Ltd, Bengaluru, Karnataka, India

\section{Abstract}

An uncontrolled increase in cytokine production may lead to systemic hyperinflammation, vascular hypo-responsiveness, increased endothelial permeability, hypercoagulation, multi-organ dysfunction and eventually death in moderate to severely ill COVID-19 patients. Targeting Tcells, an important driver of the hyperinflammatory response, in the treatment of COVID-19, could potentially reduce mortality and improve survival rates. Itolizumab is an anti-CD6 humanized monoclonal antibody with an immunomodulating action on $\mathrm{T}_{\text {effector }}$ cells that downregulates $\mathrm{T}$-cell activation, proliferation and subsequent production of various chemokines and cytokines. The efficacy and safety of Itolizumab for the treatment of cytokine release syndrome in patients with moderate to severe acute respiratory distress syndrome (ARDS) due to COVID-19 was evaluated in a multi-centric, open-label, two-arm, controlled, randomized, phase 2 study. Eligible patients 
were randomized (2:1) to arm A (best supportive care + Itolizumab) and arm B (best supportive care). The primary outcome of interest was reduction in all-cause mortality 30 days after enrolment. Thirty-six patients were screened, 5 were treated as first dose sentinels and the rest were randomized, whilst 4 patients were considered screen failures. Two patients in the Itolizumab treatment arm discontinued prior to receiving the first dose and were replaced. At the end of 1 month, there were 3 deaths in arm $B$, and none in arm A $(p=0.0296)$. At the end of the follow-up period, more patients in Arm A had improved SpO2 without increasing FiO2 ( $\mathrm{p}=0.0296)$, improved $\mathrm{PaO} 2(\mathrm{p}=0.0296)$, and reduction in IL-6 (43 pg/ml vs $212 \mathrm{pg} / \mathrm{ml} ; \mathrm{p}=0.0296)$ and tumor necrotic factor- $\alpha(9 \mathrm{pg} / \mathrm{ml}$ vs $39 \mathrm{pg} / \mathrm{ml} ; \mathrm{p}=0.0253)$ levels. Itolizumab was generally safe and well tolerated, and transient lymphopenia (11 patients in Arm A) and infusion reactions (7 patients) were the commonly reported treatment related safety events. These encouraging results indicate that larger clinical trials are warranted to establish the role of Itolizumab in controlling immune hyperactivation in COVID-19.

Trial registry number: CTRI/2020/05/024959 


\section{Introduction}

Severe acute respiratory syndrome coronavirus-2 (SARS-CoV-2; COVID-19) poses a serious global concern for public health, with millions of people infected worldwide and more than a million dead $[1,2]$. Three escalating phases of SARS-CoV-2 disease progression have been reported $[3,4]$. During the early infection phase, the virus infiltrates the lung parenchyma and proliferates causing mild constitutional symptoms. The second phase is characterized by adaptive immunity stimulation (vasodilation, endothelial permeability, leukocyte recruitment and tissue damage) with lung injury and hypoxemia as underlying causes of the respiratory dysfunction (pulmonary phase). Lung vascular thrombosis may be predominant during this phase. In the third phase (hyperinflammation phase), systemic inflammatory response may set in leading to increased production of a series of cytokines and prime adaptive T- and B-cell responses [5]. SARS-CoV-2 infection sets off an inflammatory cascade resulting in an increased release of pro-inflammatory cytokines and chemokines, especially IL-1, IL-6, IL-12, IFN- $\gamma$, and TNF- $\alpha$ [6]. These proinflammatory molecules potentiate a Th1 (T helper-1) response, causing the recruitment of monocytes and $\mathrm{T}$ lymphocytes resulting in peripheral lymphopenia and higher neutrophil:lymphocyte ratio typically observed in patients suffering from COVID-19 [7-9]. If untreated, this cytokine release syndrome may lead to vascular hypo-responsiveness, increased endothelial permeability, hypercoagulation, multi-organ dysfunction and eventually death [4].

Targeting T cells and their involvement in cytokine release syndrome during the management of SARS-CoV-2 disease has been one of the therapeutic strategies adopted to improve survival rates and reduce mortality. Unlike the other anti-inflammatory agents such as Tocilizumab (IL-6 inhibitor), Sarilumab (IL-6R inhibitor), and Anakinra (IL-1R inhibitor), Itolizumab (CD6 
inhibitor) has an upstream immunomodulating mechanism of action [10-12]. CD6 is a costimulatory receptor differentially expressed on T-cells, subsets of innate lymphoid and natural killer cells, but not on T regulatory cells [13-15]. It is implicated in the pathogenesis of multiple autoimmune and inflammatory diseases. The binding of CD6 to the activated leukocyte cell adhesion molecule (ALCAM), expressed in both the antigen presenting cells and endothelial/epithelial tissue, including the blood-brain barrier, skin, gut, lung and kidney, can modulate T-cell activity and trafficking [16].

Itolizumab is a humanized IgG1 kappa anti-CD6 monoclonal antibody that binds to domain 1 of human CD6. It selectively targets the CD6-ALCAM pathway resulting in decreased levels of IFN$\gamma$, IL-6, and TNF- $\alpha$ through Th-1 pathway and IL-17, IL-6, TNF $\alpha$ through Th-17 pathway $[17,18]$. Itolizumab thereby leads to a reduction in the T-cell infiltration at the sites of inflammation, without inducing T-cell or B-cell depletion [17].

Itolizumab has been approved in India for the treatment of moderate-to-severe chronic plaque psoriasis for the last seven years $[19,20]$ and in addition to a favorable safety profile in Phase 2 and Phase 3 trials, has shown promising results when used in psoriatic arthritis [10] and rheumatoid arthritis [21]. Itolizumab has demonstrated a durable therapeutic effect which is noted even after discontinuation of the treatment [22] in the management of psoriatic arthritis [23,24] and rheumatoid arthritis [21]. Previous studies have shown the impact of Itolizumab on human Th1 cells [17]. It has been demonstrated that even under the classical co-stimulation by anti-CD3 and anti- CD28 [25], Itolizumab is able to down-regulate the expression of key Th17 determining transcription factors and effector cytokines (i.e., IL-17) in addition to decreasing Th1 effector cytokine (IFN- $\gamma)($ Figure 1). 


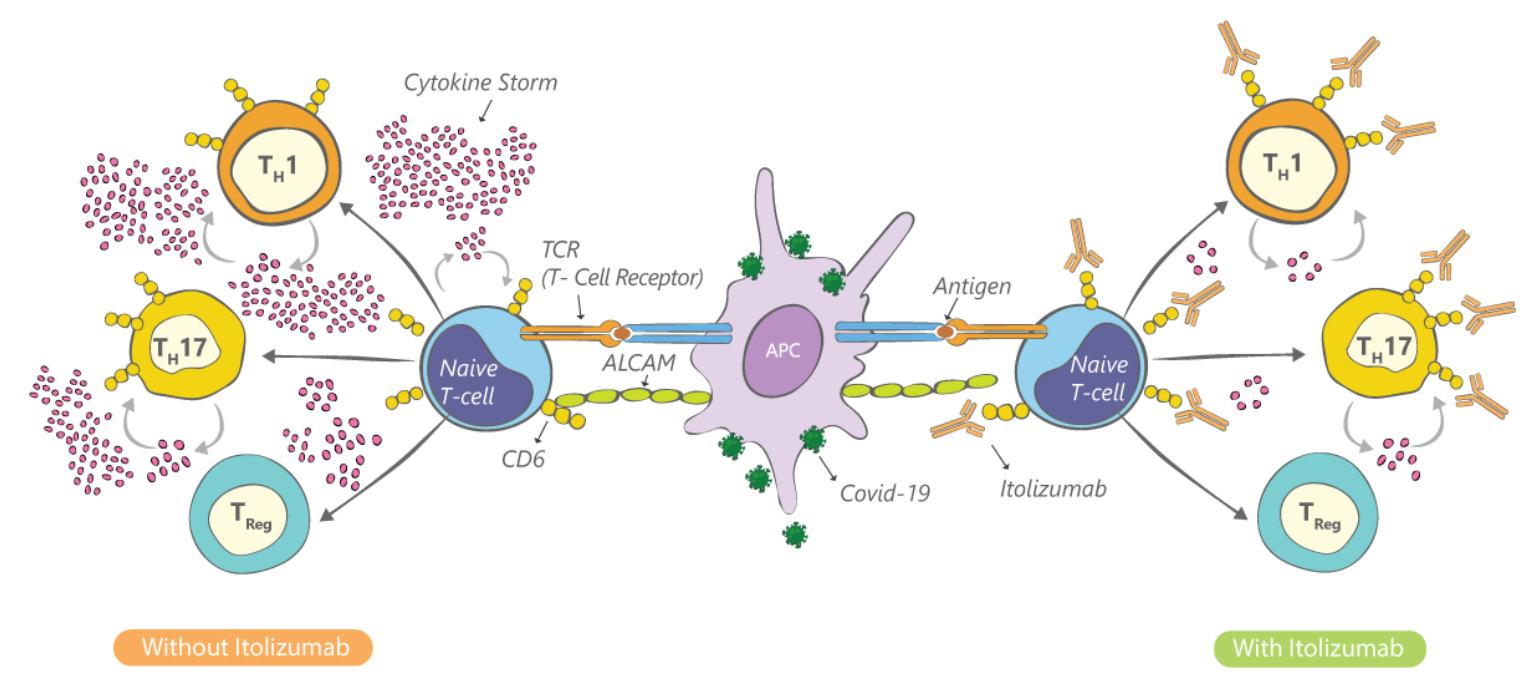

Figure 1: Itolizumab mechanism of action in COVID-19 infection.

CD6 is expressed mainly on effector T cells (Teff). CD6 stimulates ALCAM mediated T-cell activation and subsequently pro-inflammatory cytokines release. Itolizumab inhibits T-cell activation and lowers major pro-inflammatory cytokines of the Th1/Th17 pathways.

We hypothesized that Itolizumab will control the pro-inflammatory cytokine release in COVID19 patients by immunomodulation of Teff function and trafficking to the inflammation site, sparing Tregs and preserving the anti-viral response, reducing morbidity and mortality. The current study was undertaken to estimate the efficacy and safety of Itolizumab in the treatment of cytokine release syndrome in patients with moderate to severe acute respiratory distress syndrome (ARDS) due to COVID-19.

\section{Methods:}

\section{Study design}

This was an open-label, two-arm, randomized, controlled, multi-centric, phase-2 study conducted in 4 designated COVID-19 hospitals in India. Initial dosing was done for first five patients in a 
staggered manner wherein after a patient was dosed, safety was monitored for 24-48 hours prior to dosing of the next patient. Once all five patients were dosed in this staggered manner, subsequent patients were enrolled such that study had patients randomized in a 2:1 ratio. Randomization was centrally done using computer-generated sequences (SAS version 9.4). Patients who were randomized, but did not receive the full infusion, were considered unevaluable and the same randomization code was used for allocation of the next patient enrolled by the study site. The CONSORT flow diagram for the study is summarized in Figure 2. The study was initiated on May 2, 2020, and all patients were followed up for 30 days, with the study closing out on July 7, 2020 when the follow up period of the final patient was completed and all patients in the trial had either been discharged from clinical care or died from COVID-19 complications. 
medRxiv preprint doi: https://doi.org/10.1101/2020.12.01.20239574; this version posted December 2, 2020. The copyright holder for this preprint (which was not certified by peer review) is the author/funder, who has granted medRxiv a license to display the preprint in perpetuity.

It is made available under a CC-BY-NC-ND 4.0 International license .

Figure 2. CONSORT 2010 Flow Diagram

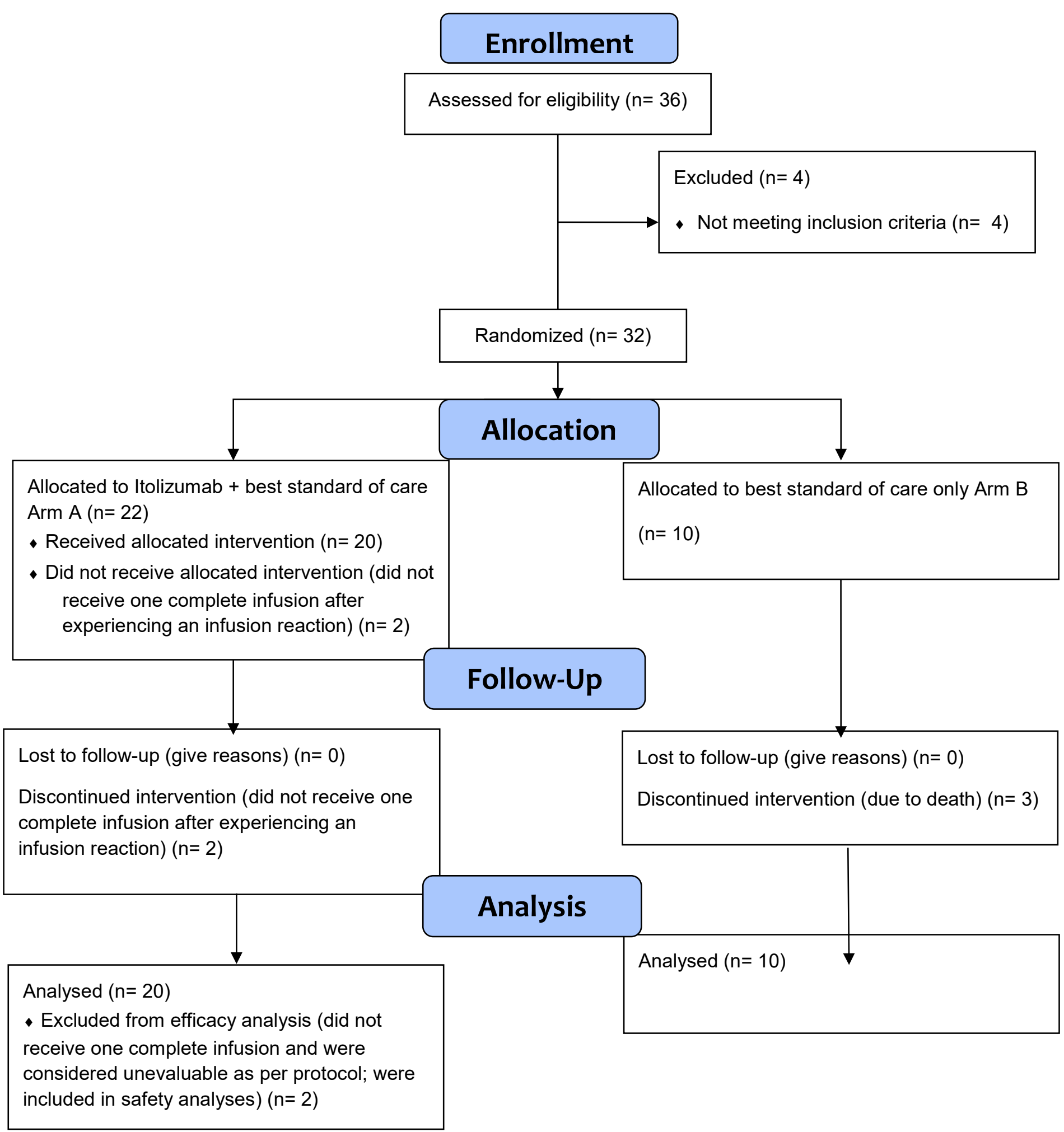




\section{Study subjects}

Adult male or female patients above 18 years, who tested positive for virologic diagnosis of SARSCoV-2 infection (RT-PCR), and who were hospitalized due to clinical worsening with oxygen saturation of $\leq 94 \%$ at rest in ambient air, were eligible for randomization if they had either moderate to severe ARDS or high levels of proinflammatory markers. Patients were defined to have moderate to severe ARDS if they had $\mathrm{PaO} 2 /$ Fio2 ratio of $<200$ or more than $25 \%$ deterioration from the immediate previous value. Alternatively, the proinflammatory markers included were baseline serum ferritin level $\geq 400 \mathrm{ng} / \mathrm{mL}$ or IL-6 levels greater than 4 times of upper limits of normal value.

Major exclusion criteria included - known severe allergic reactions to monoclonal antibodies, an active tuberculosis (TB) infection/inadequately treated tuberculosis/latent tuberculosis, on oral anti-rejection or any immune-suppressive drugs in last 6 months, those who participated in other drug clinical trials using anti-IL-6 therapy. Patients with a known history of Hepatitis B, Hepatitis $\mathrm{C}$ or HIV, absolute neutrophils count $(\mathrm{ANC})<1000 / \mathrm{mm}^{3}$, platelet count $<50,000 / \mathrm{mm}^{3}$ and absolute lymphocyte count (ALC) $<500 / \mathrm{mm}^{3}$ were also excluded.

\section{Study Settings}

The study was carried out at four COVID-19 specific, tertiary hospitals in India. Two of these sites were in New Delhi, and two were in Mumbai. All four sites were tertiary, teaching hospitals, with considerable experience of undertaking clinical trials. 


\section{Treatments}

Most commonly used therapies as part of best supportive care in both treatment arms included oxygen, antibiotics, hydroxychloroquine, antivirals, steroids, low-molecular-weight heparin, and vitamin supplements.

The dose of Itolizumab was calculated and diluted in $250 \mathrm{ml}$ of normal $(0.9 \%)$ saline; this was allowed to reach room temperature prior to infusion. Itolizumab infusion in Arm A started after premedication with hydrocortisone $100 \mathrm{mg}$ i.v (or equivalent short acting glucocorticoid) and Pheniramine $30 \mathrm{mg}$ per i.v. about $30 \pm 10$ minutes prior to infusion. Patients were initiated on 1.6 $\mathrm{mg} / \mathrm{kg}$ dose iv infusion of Itolizumab and continued with $0.8 \mathrm{mg} / \mathrm{kg}$ dose weekly regimen as required. Subsequent doses were modified, deferred, or stopped as per the investigator's discretion if the patient recovered. The Itolizumab infusion was administered over a period not less than 120 minutes, using an infusion set with an in-line, sterile, non-pyrogenic, low protein-binding filter (pore size of $1.2 \mu \mathrm{m}$ or less). Approximately $50 \mathrm{~mL}$ of infusion solution was administered during the first hour, followed by remaining solution (approximately $200 \mathrm{~mL}$ ) in the next hour. Infusion period could be extended up to 8 hours for medical reasons, particularly if the patient experienced infusion related reactions, which needed medical attention prior to re-initiation of infusion. Itolizumab was not infused concomitantly in the same IV line with any other agents.

\section{Ethics}

This study was carried out in accordance with the ethical principles described in the Declaration of Helsinki (64th WMA General Assembly, Fortaleza, Brazil, October 2013), the International Council for Harmonization Good Clinical Practice (ICH GCP) E6 (R2), and New Drugs and Clinical Trials Rule 2019 issued by the Government of India. The study received approvals from 
the IECs/IRBs of all the participating sites. All the IECs/IRBs had active CDSCO registration at the time of approving this study. Subjects provided written informed consent prior to initiation of the study procedures. Study data was periodically reviewed by a data and safety monitoring board (DSMB).

\section{Study Objectives and Endpoints}

The primary objective of this study was to estimate the efficacy and safety of Itolizumab in the treatment of cytokine release syndrome in patients with moderate to severe ARDS due to COVID19. Secondary Objective was to assess possible correlations/associations between cytokine markers and clinical efficacy/safety.

The study's primary outcome measures included:

1. Reduction in mortality one month after randomization

2. Reduction in the proportion of patients with deteriorating lung functions, as measured by:

a. Stable $\mathrm{SpO} 2$ without increasing $\mathrm{FiO} 2$

b. Stable $\mathrm{PaO} 2$ without increasing $\mathrm{FiO} 2$

3. Reduction in proportion of patients who needed non-invasive ventilation, invasive mechanical ventilation/endotracheal intubation, and high flow nasal oxygen

4. Reduction in inflammatory markers: Ferritin, D-dimer, LDH, CRP.

Key secondary outcome measures included measurement of:

1. Biomarkers such as IL-6, TNF- $\alpha$, IL-17A

2. Absolute lymphocyte count

3. $\mathrm{PaO} 2 / \mathrm{FiO} 2$ ratio calculated from arterial blood gas analyses 
4. Safety: Number of participants with treatment-related side effects as assessed by Common Terminology Criteria for Adverse Event (CTCAE) version 5.0

\section{Biomarker assessments}

Blood samples were collected for analysis of cytokines/chemokines.

\section{Statistical analysis}

For this Phase 2 study, we considered enrolling 30 patients. Continuous variables were summarized using descriptive statistics such as mean, standard deviation, $95 \%$ confidence interval (CI), or median with range, as appropriate. Categorical variables were summarized using proportions (counts and percentages). Comparisons between proportions was done using Fisher's exact test since the sample size was small. For continuous variables, change from baseline or trend in change over time were tabulated, as appropriate. All statistical tests were performed at 5\% level of significance (two-sided test) and p-value $<0.05$ considered statistically significant. All statistical analysis was performed using $\mathrm{SAS}^{\circledR}$ (version 9.4) software.

\section{Trial Registration Details}

The trial protocol was registered with the Clinical Trials Registry of India (CTRI). The CTRI registration number is CTRI/2020/05/024959 and it can be accessed at this link: http://ctri.nic.in/Clinicaltrials/showallp.php?mid1=42878\&EncHid=\&userName=itolizumab. The trial was prospectively registered with the CTRI, which is the government mandated registry for trials in India. 


\section{Results}

\section{Participant disposition and baseline characteristics}

A total of 36 patients were screened of which 4 were considered screen failures; 1 patient was COVID-19 negative and ALC count of 3 patients was $<500$ cells/cu.mm. A total of 32 patients were randomized: 22 patients in Arm A and 10 patients in Arm B (Table 1). Two patients from Arm A discontinued treatment prior to completion of first dosing due to infusion related reactions and were replaced as defined above. The events of infusion related reactions (IRRs) resolved on the same day and the patients continued to receive best supportive care. A total of 27 patients (Arm A: 20 and Arm B: 7) completed the study; 3 patients in Arm B discontinued due to death. All 20 patients in Arm A had at least one complete infusion of Itolizumab; of these, 7 patients had two infusions; 3 patients had three infusions and 4 patients had four infusions.

\section{Table 1: Participant disposition}

\begin{tabular}{|c|c|c|}
\hline Variable & $\begin{array}{l}\text { Arm A } \\
(\mathrm{N}=\mathbf{2 0})\end{array}$ & $\begin{array}{l}\text { Arm B } \\
(\mathrm{N}=10)\end{array}$ \\
\hline FAS Population, ${ }^{*} \mathrm{n}(\%)$ & $20(100.00)$ & $10(100.00)$ \\
\hline Safety Population, ${ }^{* *}$ n $(\%)$ & $22(110.00)$ & $10(100.00)$ \\
\hline \multicolumn{3}{|l|}{ Completed the study, n (\%) } \\
\hline Completed 30 days follow up in hospital & $4(20.00)$ & $1(10.00)$ \\
\hline Early discharged** & $16(80.00)$ & $6(60.00)$ \\
\hline Discontinued & - & $3(30.00)$ \\
\hline \multicolumn{3}{|l|}{$\overline{\text { Reasons for Discontinuation, } \mathrm{n}(\%)}$} \\
\hline Death & - & $3(30.00)$ \\
\hline
\end{tabular}

*FAS: Full analysis set defined as all patients randomized and those who received at least one full dose of Itolizumab (Arm A); Safety population was defined as all patients randomized (in Arm B) and those who received partial or full dose of Itolizumab (in Arm A)

**2 subjects could not complete even one dosing and were replaced as per protocol 
The median age of patients in Arm A was 50.5 years and in Arm B was 49.5 years (Table 2). All patients were of Asian ethnicity with most of the patients being male (Arm A: 95\% and Arm B: $70 \%)$

The mean duration of COVID-19 related symptoms at enrolment was 8.6 days and 5.6 days for Arms A and B, respectively, and the difference was not statistically significant. The most frequently reported COVID-19 related symptoms in both treatment arms were fever and dyspnea, followed by cough and tachypnea. Hypertension was the most common active co-morbid condition (20\% in each arm).

Table 2: Demographic and baseline characteristics

\begin{tabular}{|c|c|c|}
\hline Variable & $\begin{array}{l}\text { Arm A } \\
(N=20)\end{array}$ & $\begin{array}{l}\text { Arm B } \\
(\mathrm{N}=10)\end{array}$ \\
\hline \multicolumn{3}{|l|}{ Age (years) } \\
\hline $\mathrm{N}$ & 20 & 10 \\
\hline Mean(SD) & $49.55(12.49)$ & $48.30(14.62)$ \\
\hline \multicolumn{3}{|l|}{ Sex, n (\%) } \\
\hline Female & $1(5.00)$ & $3(30.00)$ \\
\hline Male & $19(95.00)$ & $7(70.00)$ \\
\hline \multicolumn{3}{|l|}{ Race, n (\%) } \\
\hline Asian & $20(100.00)$ & $10(100.00)$ \\
\hline \multicolumn{3}{|l|}{ Ethnicity, n (\%) } \\
\hline South Asian & $19(95.00)$ & $10(100.00)$ \\
\hline Southeast Asian & $1(5.00)$ & - \\
\hline D-Dimer (mcg/ml (FEU)) & $3.50(4.87)$ & $5.15(7.85)$ \\
\hline \multicolumn{3}{|l|}{ Mean (SD) } \\
\hline D-Dimer (mcg/ml (FEU)) & $1.86(0.28-20.0)$ & $1.59(0.28-20.0)$ \\
\hline \multicolumn{3}{|l|}{ Median (Range) } \\
\hline$\overline{\text { Ferritin (ng/ml) }}$ & $943.34(756.06)$ & $577.95(336.73)$ \\
\hline
\end{tabular}




\begin{tabular}{lll}
\hline Variable & $\begin{array}{c}\text { Arm A } \\
(\mathbf{N}=\mathbf{2 0})\end{array}$ & $\begin{array}{c}\text { Arm B } \\
(\mathbf{N}=\mathbf{1 0})\end{array}$ \\
\hline Mean (SD) & & \\
\hline Ferritin (ng/ml) & $669.79(100-2550.7)$ & $496.93(90.70-1290.2)$ \\
Median (Range) & &
\end{tabular}

\begin{tabular}{lll}
\hline $\mathrm{LDH}(\mathrm{U} / \mathrm{L})$ & $533.3(206.85)$ & $645.3(292.79)$
\end{tabular}

Mean (SD)

$\mathrm{LDH}(\mathrm{U} / \mathrm{L}) \quad 512(254-1125) \quad 555(375-1150)$

Median (Range)

C-Reactive Protein (mg/L) $\quad 73.74(71.84) \quad 103.88(87.89)$

Mean (SD)

\begin{tabular}{lll}
\hline C-Reactive Protein $(\mathrm{mg} / \mathrm{L})$ & $58.15(5.47-254.3)$ & $76.9(19.90-275.4)$
\end{tabular}

Median (Range)

\begin{tabular}{lllll}
\hline Duration of & COVID-19 & related & $8.55(6.21)$ & $5.60(2.59)$
\end{tabular}

symptoms at enrolment (in Days)

Mean (SD)

Duration of COVID-19 $\quad$ related $7.5(1-26) \quad 5.5(3-11)$

symptoms at enrolment (in Days)

Median (Range)

Absolute Lymphocyte Count $\quad 969.85$ (407.70) 1357.3 (492.30)

Mean (SD)

\section{Primary outcome measures}

\section{Mortality at 1 month}

Itolizumab treatment had a noticeable improvement on patient's survival through reduction in 1month mortality rate. A statistically significant difference $(\mathrm{p}=0.0296 ; 95 \% \mathrm{CI}=-0.3[-0.61,-0.08]))$ in the 1-month mortality rate was observed between the 2 treatment arms. Three deaths were reported in Arm B on Days 4, 5 and 12 (1 due to acute respiratory distress syndrome and 2 due to respiratory failure). There were no deaths in Arm A. 


\section{Lung function determined by $\mathrm{SpO} 2$ and $\mathrm{PaO} 2$}

\section{a. Stable/improved SpO2}

A higher proportion of patients in Arm A had stable/improved $\mathrm{SpO} 2$ without increasing $\mathrm{FiO} 2$ in all the post-baseline assessment visits in comparison to Arm B (Table 3). A significant difference was observed between the 2 arms from Day 21 onwards; 100\% of the participants in Arm A showed favorable outcomes compared to only $70 \%$ in Arm B ( $\mathrm{p}=0.0296)$.

Table 3: Patients with Stable/Improved SpO2 without Increasing FiO2*

\begin{tabular}{lccc}
\hline Visit & $\begin{array}{c}\text { Arm A } \\
(\mathbf{N}=\mathbf{2 0})\end{array}$ & $\begin{array}{c}\text { Arm B } \\
(\mathbf{N}=\mathbf{1 0})\end{array}$ & P-value \\
\hline Day 7 & $17(85.00)$ & $5(50.00)$ & 0.0778 \\
Day 14** & $19(95.00)$ & $7(70.00)$ & 0.0952 \\
Day 21 & $20(100.00)$ & $7(70.00)$ & 0.0296 \\
Day 30 & $20(100.00)$ & $7(70.00)$ & 0.0296 \\
\hline
\end{tabular}

* Stable $\mathrm{SpO} 2$ was defined as absence of increase in $\mathrm{FiO} 2$ to maintain $\mathrm{Spo} 2 \geq 92 \%$ and improvement of $\mathrm{SpO} 2$ was defined as decrease in $\mathrm{FiO} 2$ to maintain $\mathrm{SpO} 2>92 \%$.

** Patients improved/ weaned off O2, the observation was carried forward; 3 patients in Arm B died on Day 4, 5 and 12; $\mathrm{p}$-value between arm is estimated using Fisher's exact test ( $\mathrm{p}$-value $<0.05$ is considered significant)

\section{b. Stable/Improved PaO2}

A higher proportion of patients in Arm A had stable $\mathrm{PaO} 2$ without increasing $\mathrm{FiO} 2$ in all the postbaseline assessment visits in comparison to Arm B (Table 4). Significant difference was observed Day 21 onwards; $100 \%$ in Arm A compared to $70 \%$ in Arm B ( $\mathrm{p}=0.0296)$.

Table 4: Patients with Stable/Improved $\mathrm{PaO} 2$ Without Increasing FiO2*

\begin{tabular}{lccc}
\hline Visit & $\begin{array}{l}\text { Arm A } \\
(\mathbf{N}=\mathbf{2 0})\end{array}$ & $\begin{array}{l}\text { Arm B } \\
(\mathbf{N}=\mathbf{1 0})\end{array}$ & P-value \\
\hline Day 7 & $18(90.00)$ & $6(60.00)$ & 0.1413 \\
Day 14** & $19(95.00)$ & $7(70.00)$ & 0.0952
\end{tabular}




\begin{tabular}{lccc}
\hline Visit & $\begin{array}{c}\text { Arm A } \\
(\mathbf{N}=\mathbf{2 0})\end{array}$ & $\begin{array}{c}\text { Arm B } \\
(\mathbf{N}=\mathbf{1 0})\end{array}$ & P-value \\
\hline Day 21 & $20(100.00)$ & $7(70.00)$ & 0.0296 \\
Day 30 & $20(100.00)$ & $7(70.00)$ & 0.0296
\end{tabular}

* Stable $\mathrm{PaO} 2$ was defined as up to $10 \%$ change in $\mathrm{PaO} 2 / \mathrm{FiO} 2$ ratio from baseline while an improvement of $\mathrm{PaO} 2$ was defined as $>10 \%$ improvement in $\mathrm{PaO} 2 / \mathrm{FiO} 2$ ratio from baseline (including patients weaned off oxygen).

** Patients improved/ weaned off O2, the observation was carried forward; 3 patients in Arm B died on Days 4, 5 and 12; $p$-value between arm is estimated using Fisher's exact test ( $\mathrm{p}$-value $<0.05$ is considered significant)

\section{Non-invasive ventilation, invasive mechanical ventilation/endotracheal intubation, and high flow nasal oxygen}

In Arm A, there were 5 patients on NIV (BiPAP or CPAP) at baseline that improved and came off NIV by Day 14. In Arm B, there were 4 patients on NIV at baseline of which 1 patient improved and came off NIV by Day 14. Condition of the 3 remaining patients in Arm B, which included 1 patient who continued to be on NIV and 2 patients who progressed to IMV before Day 7, further worsened and all of them died by Day 12. All the patients in Arm A were progressively weaned off oxygen by Day 30, with 5, 14, 18 and 20 patients getting weaned by days 7, 14, 21 and 30, respectively. In Arm B, 2, 4, 6 and 7 patients were progressively weaned off oxygen on Days 7, 14,21 and 30 respectively.

\section{Inflammatory Markers (related to primary outcomes)}

\section{a. Ferritin}

Baseline ferritin was high in Arm A compared to Arm B (943.34 ng/mL vs 577.95 ng/mL). In Arm A, the mean ferritin reduced to 303.50 (SD 210.93) ng/dL and 189.22 (SD 129.96) ng/dL on Day 14 and 30, respectively. In Arm B, the ferritin was 367.68 (SD 130.22) ng/dL and 285.25 (SD 157.76) $\mathrm{ng} / \mathrm{dL}$ on Days 14 and 30, respectively. A greater reduction from baseline in serum ferritin levels was seen in Arm A (-479.3 (620.95) ng/dL) in comparison to Arm B (-234.4 (405.67) ng/dL) at day 30 . 


\section{b. D-dimer}

Baseline D-dimer was higher in Arm B (5.15 (SD 7.85) $\mu \mathrm{g} / \mathrm{mL})$ compared to Arm A (3.50 (SD 4.87) $\mu \mathrm{g} / \mathrm{mL}$ ). In Arm A, mean D-dimer reduced to 2.83 (SD 5.46) $\mu \mathrm{g} / \mathrm{mL}$ and 0.41 (SD 0.18) $\mu \mathrm{g} / \mathrm{mL}$ on Days 14 and 30, respectively. In Arm B, mean D-dimer was 0.86 (SD 0.71) $\mu \mathrm{g} / \mathrm{mL}$ and 1.15 (SD 0.37) $\mu \mathrm{g} / \mathrm{mL}$ on Days 14 and 30, respectively. Eight patients in Arm A and five patients in Arm B received low-molecular-weight heparin.

\section{c. $\mathbf{L D H}$}

Baseline LDH was comparable in both arms; 533.30 (SD 206.85) U/L in Arm A and 645.30 (SD 292.79) U/L in Arm B. In Arm A, mean LDH reduced to 381.47 (SD 181.45) U/L and 208.67 (SD 40.72) U/L on Days 14 and 30, respectively. In Arm B, mean LDH was 330.20 (SD 91.63) U/L and 456.50(SD 173.24) U/L on Days 14 and 30, respectively.

\section{d. CRP}

Baseline CRP was numerically higher in Arm B; 73.74 (SD 71.84) mg/L in Arm A vs 103.88 (SD 87.89) $\mathrm{mg} / \mathrm{L}$ in Arm B. After randomization in Arm A, mean CRP reduced to 6.45 (SD 4.14) mg/L and 13.69 (SD 20.45) mg/L on Days 14 and 30, respectively. In Arm B, mean CRP was 14.36 (9.29) $\mathrm{mg} / \mathrm{L}$ and 3.05 (2.62) $\mathrm{mg} / \mathrm{L}$ on Days 14 and 30, respectively.

The improvement in the biomarker status over time is captured in table 5 which outlines the mean change from baseline values over time. Number of patients at each time point varied due to patients reaching the end of follow up either due to discharge from clinical care or death. 
Table 5. Mean change from baseline values for inflammatory markers

\begin{tabular}{|c|c|c|c|c|}
\hline \multicolumn{5}{|c|}{ Ferritin (ng/mL) } \\
\hline & Day 7 & Day 14 & Day 21 & Day 30 \\
\hline Arm A & -117.8 & -713.9 & -780.9 & -479.3 \\
\hline $\mathrm{N}^{*}$ & 18 & 15 & 11 & 3 \\
\hline Arm B & -87.05 & -209.6 & 4238 & -234.4 \\
\hline $\mathrm{N}^{* *}$ & 7 & 5 & 3 & 2 \\
\hline \multicolumn{5}{|c|}{ D-dimer $(\mu \mathrm{g} / \mathrm{mL}$ FEU $)$} \\
\hline & Day 7 & Day 14 & Day 21 & Day 30 \\
\hline Arm A & -1.43 & -0.45 & -4.35 & -2.63 \\
\hline $\mathrm{N}^{*}$ & 18 & 12 & 11 & 3 \\
\hline Arm B & 2.3 & -0.68 & 8.54 & -0.35 \\
\hline $\mathrm{N}^{* *}$ & 7 & 4 & 2 & 2 \\
\hline \multicolumn{5}{|c|}{ LDH (U/L) } \\
\hline & Day 7 & Day 14 & Day 21 & Day 30 \\
\hline Arm A & -134 & -195.8 & -308.1 & -212.7 \\
\hline $\mathrm{N}^{*}$ & 18 & 15 & 11 & 3 \\
\hline Arm B & -44.29 & -195.2 & 155.33 & -97 \\
\hline $\mathrm{N}^{* *}$ & 7 & 5 & 3 & 2 \\
\hline \multicolumn{5}{|c|}{ CRP (mg/L) } \\
\hline & Day 7 & Day 14 & Day 21 & Day 30 \\
\hline Arm A & -61.69 & -81.65 & -90.99 & -103.2 \\
\hline $\mathrm{N}^{*}$ & 18 & 16 & 11 & 3 \\
\hline Arm B & -103.6 & -107.2 & -127.5 & -127.6 \\
\hline $\mathrm{N}^{* *}$ & 8 & 5 & 3 & 2 \\
\hline
\end{tabular}

* Number of patients in Arm A at given time points

** Number of patients in Arm B at given time points 


\section{Secondary outcome measures}

\section{Biomarkers}

\section{a. IL-6}

Mean baseline value of IL-6 was comparable in both arms; $159.09 \mathrm{pg} / \mathrm{mL}$ in Arm A and 162.16 $\mathrm{pg} / \mathrm{mL}$ in Arm B. A significant decline ( $\mathrm{p}=0.0269)$ in mean IL-6 levels post first infusion was seen in Arm A (42.98 pg/mL) compared to Arm B (211.52 pg/mL) (Figure 3).

\section{Figure 3. Mean IL-6 values}

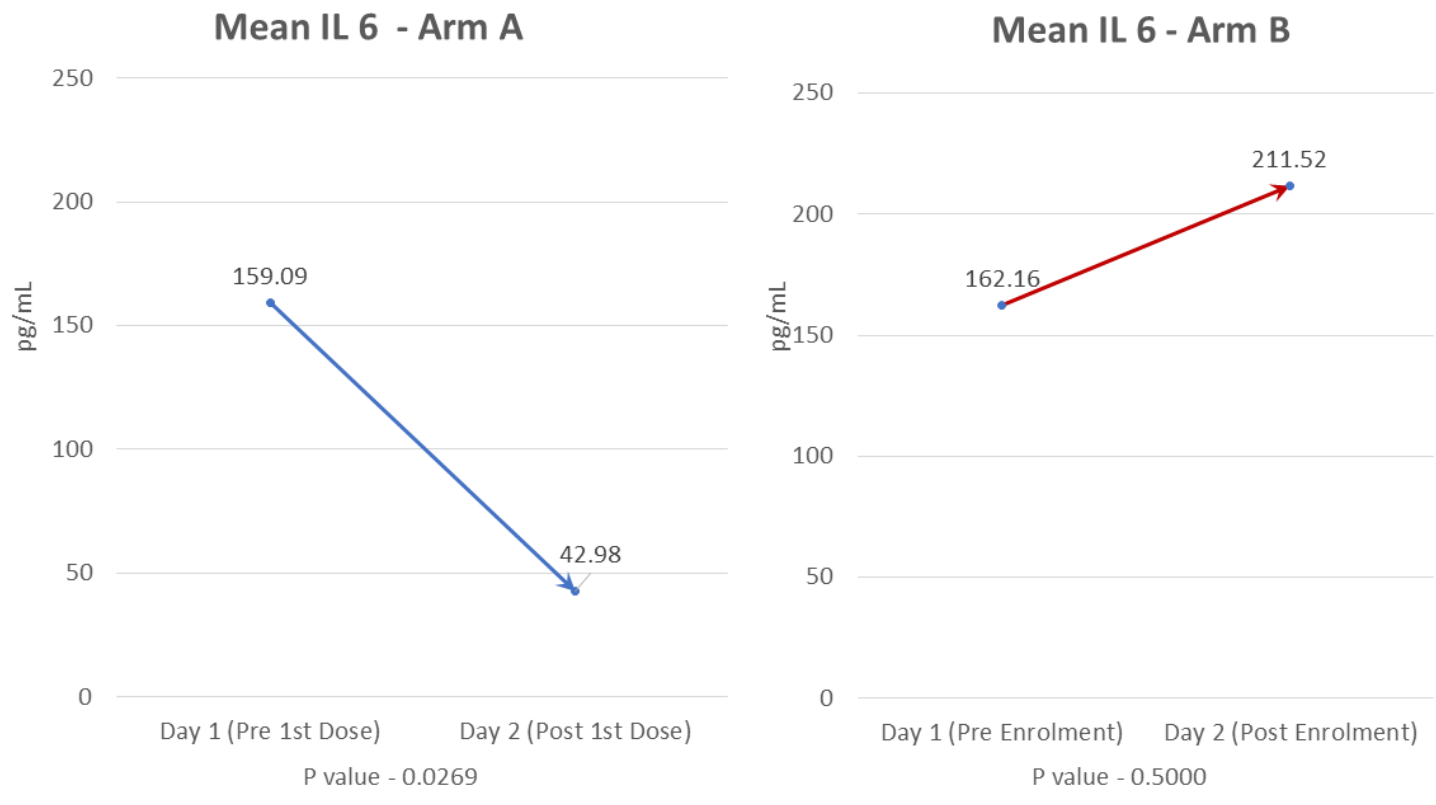

\section{b. TNF- $\alpha$}

Mean baseline value of TNF $\alpha$ was higher in Arm A (43.64 pg/mL) than in Arm B (11.26 pg/mL). A significant decline $(\mathrm{p}=0.0253)$ in mean TNF- $\alpha$ levels post first infusion was seen in Arm A (8.87 pg/mL) compared to Arm B (39.19 pg/mL) (Figure 4). 


\section{Figure 4: Mean TNF-a}
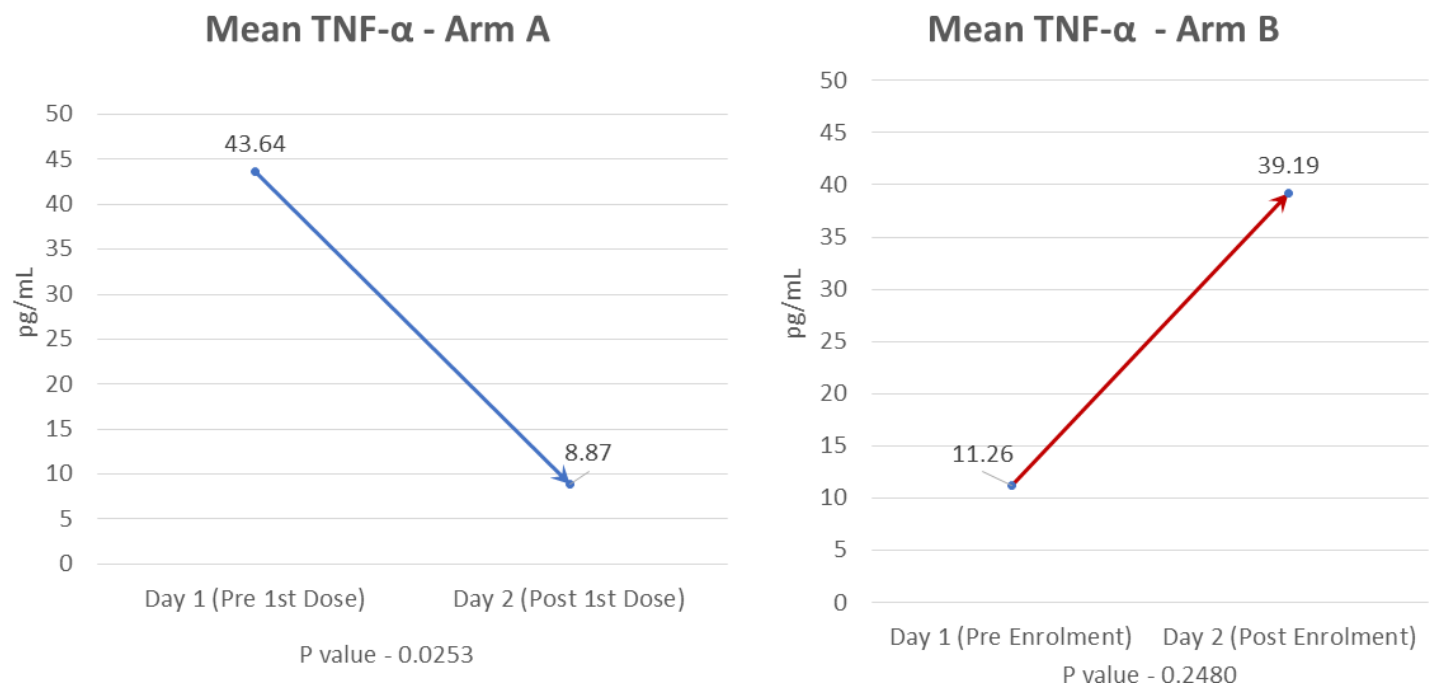

\section{c. IL-17A}

Mean baseline value of IL-17A was comparable in both arms; $10.36 \mathrm{pg} / \mathrm{mL}$ in Arm A and 9.83 $\mathrm{pg} / \mathrm{mL}$ in Arm B. A notable decline in mean IL-17A levels post first infusion was seen in Arm A (6.75 pg/mL) unlike in Arm B, where there was an increase $(14.75 \mathrm{pg} / \mathrm{mL})$.

\section{Absolute Lymphocyte Count}

Baseline ALC was numerically lower in Arm A (969.85 cells per mm³) than in Arm B (1357.3 cells per $\mathrm{mm}^{3}$ ). A gradual increase over time in mean ALC was seen in Arm A in comparison to Arm B (Figure 5). Eleven patients in arm A and 2 patients in Arm B had a grade 3 event of postinfusion lymphopenia, which was transient and recovered spontaneously by day 7 . 


\section{Figure 5: Mean Absolute Lymphocyte Count}

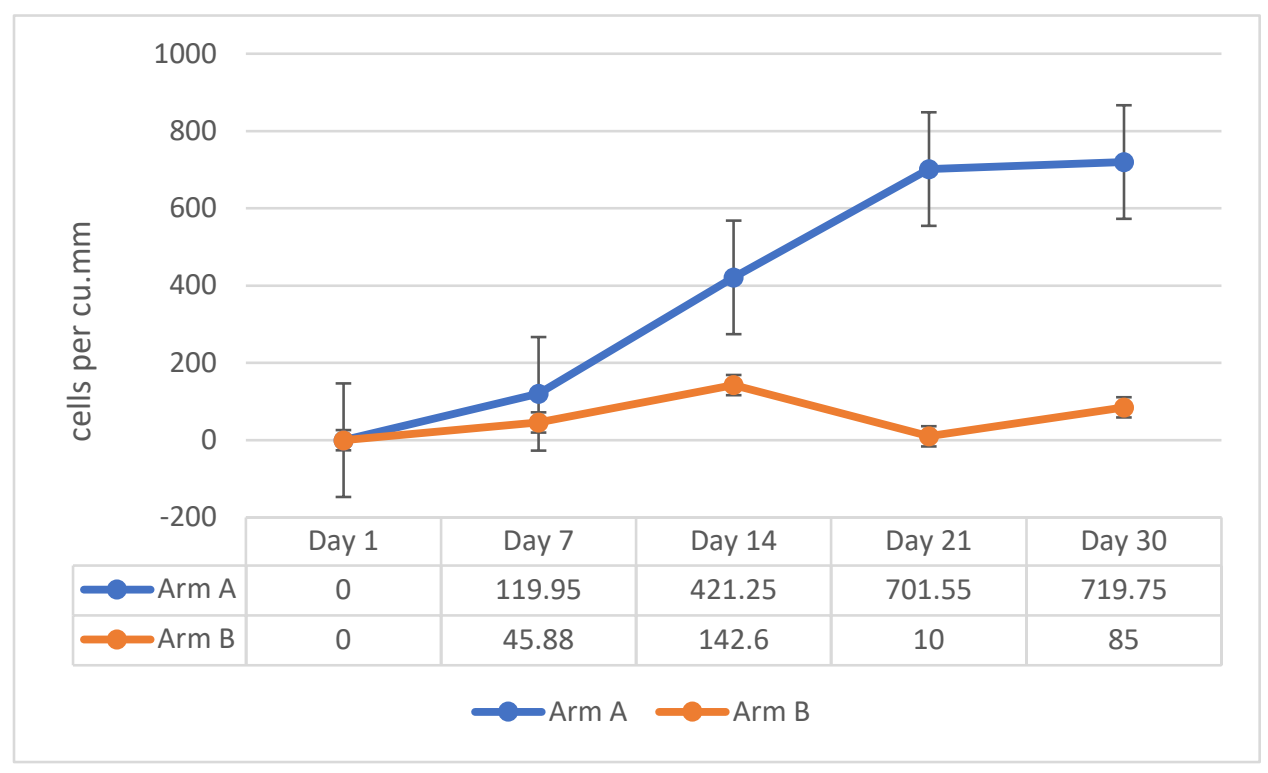

\section{3. $\mathrm{PaO} 2$ / FiO2 ratio}

At Baseline, mean $\mathrm{PaO} 2 / \mathrm{FiO} 2$ ratio was numerically higher in Arm A (126.57; SD 38.31) vs Arm $\mathrm{B}$ (114.05; $\mathrm{SD} 30.93) . \mathrm{PaO} 2 / \mathrm{FiO} 2$ ratio gradually increased over time in Arm A in comparison to Arm B. The change from baseline observed at various time points is mentioned in Table 6. Given that there were censoring events (discharged from care or death) over time, the number of patients in each arm varied at each time point.

Table 6. Mean PaO2/FiO2 ratio over time

\begin{tabular}{lccccc}
\hline & Baseline & Day 7 & Day 14 & Day 21 & Day 30/EOS \\
\hline Arm A (n) & 20 & 16 & 14 & 8 & 3 \\
Mean (SD) & $126.57(38.31)$ & $203.50(95.51)$ & $283.43(104.26)$ & $350.25(70.36)$ & $397.67(15.63)$ \\
Arm B (n) & 10 & 6 & 5 & 3 & 0 \\
Mean (SD) & $114.05(30.93)$ & $184.53(95.51)$ & $338.40(42.57)$ & $398.33(24.01)$ & \\
\hline
\end{tabular}




\section{Safety}

During the treatment period, a total of 22 patients experienced at least one treatment emergent adverse event (TEAE); 18 (81.82\%) patients in Arm A and 4 (40.00\%) patients in Arm B. Transient lymphocyte count decrease was the most commonly reported TEAE in both arms in addition to lower respiratory tract infection, ARDS and respiratory failure in Arm B (Table 7). Lymphocyte count decrease was the most frequently reported study drug related TEAE reported in $50 \%$ of patients in Arm A $(n=11)$. These events were reported between Day 2 to Day 4 and returned to normal by Day 7 .

Table 7. Treatment emergent adverse events by treatment group (Safety population)

\begin{tabular}{|c|c|c|}
\hline $\begin{array}{r}\text { System Organ Class } \\
\text { Preferred Term }\end{array}$ & $\begin{array}{l}\text { Arm A } \\
(\mathrm{N}=22)^{*}\end{array}$ & $\begin{array}{l}\text { Arm B } \\
(\mathrm{N}=10)\end{array}$ \\
\hline Cardiac disorders & $2(9.09)$ & - \\
\hline Pericardial effusion & $1(4.55)$ & - \\
\hline Sinus tachycardia & $1(4.55)$ & - \\
\hline Endocrine disorders & $1(4.55)$ & - \\
\hline Hypothyroidism & $1(4.55)$ & - \\
\hline Gastrointestinal disorders & $1(4.55)$ & - \\
\hline Constipation & $1(4.55)$ & - \\
\hline $\begin{array}{l}\text { General disorders and administration } \\
\text { site conditions }\end{array}$ & $5(22.72)$ & - \\
\hline Chills & $5(22.72)^{* *}$ & - \\
\hline Immune system disorders & $1(4.55)$ & - \\
\hline Anaphylactic reaction & $1(4.55) * *$ & - \\
\hline Infections and infestations & $1(4.55)$ & $3(30.00)$ \\
\hline Fungal infection & - & $1(10.00)$ \\
\hline Lower respiratory tract infection & - & $2(20.00)$ \\
\hline Urinary tract infection & $1(4.55)$ & - \\
\hline
\end{tabular}




\begin{tabular}{|c|c|c|}
\hline $\begin{array}{r}\text { System Organ Class } \\
\text { Preferred Term }\end{array}$ & $\begin{array}{l}\text { Arm A } \\
(\mathrm{N}=22)^{*}\end{array}$ & $\begin{array}{l}\text { Arm B } \\
(\mathrm{N}=10)\end{array}$ \\
\hline $\begin{array}{l}\text { Injury, poisoning and procedural } \\
\text { complications }\end{array}$ & $1(4.55)$ & - \\
\hline Infusion related reaction & $1(4.55)^{* *}$ & - \\
\hline Investigations & $12(54.55 \%)$ & $2(20.00)$ \\
\hline $\begin{array}{l}\text { Alanine aminotransferase } \\
\text { increased }\end{array}$ & $1(4.55)$ & - \\
\hline Fibrin D dimer increased & $1(4.55)$ & - \\
\hline Low density lipoprotein increased & $1(4.55)$ & - \\
\hline Lymphocyte count decreased & $11(50.00)^{* *}$ & $2(20.00)$ \\
\hline $\begin{array}{l}\text { Non-high-density lipoprotein } \\
\text { cholesterol increased }\end{array}$ & $1(4.55)$ & - \\
\hline Platelet count decreased & $1(4.55)^{* *}$ & - \\
\hline Metabolism and nutrition disorders & $6(27.27)$ & $1(10.00)$ \\
\hline Hyperglycemia & $4(18.18)$ & $1(10.00)$ \\
\hline Hypertriglyceridemia & $2(9.09)$ & $1(10.00)$ \\
\hline $\begin{array}{l}\text { Respiratory, thoracic, and mediastinal } \\
\text { disorders }\end{array}$ & - & $3(30.00)$ \\
\hline $\begin{array}{l}\text { Acute respiratory distress } \\
\text { syndrome }\end{array}$ & - & $2(20.00)$ \\
\hline Respiratory failure & - & $2(20.00)$ \\
\hline
\end{tabular}

* 2 subjects could not complete even one dosing and were replaced as per protocol. They are part of safety population set till their discontinuation.

** Related to the study drug

Five patients ( 2 patients in Arm A out of the patients who received complete infusion and 3 patients in Arm B) reported serious adverse events (SAEs) during the study. The SAEs reported in Arm A were anaphylactic reaction and pericardial effusion. Anaphylactic reaction resolved on the same day with medical intervention and was considered as related to the study drug infusion. Pericardial 
effusion was considered due to underlying hypothyroidism. The patient was treated with levothyroxine and recovered. The event was considered not related to the study drug.

Three deaths were reported in Arm B. The first death was due to lower respiratory tract infection with ARDS; the second was due to type 1 respiratory failure with ARDS, with lower respiratory tract infection; and the third was due to respiratory failure. No fatal TEAEs were reported in Arm A.

As defined in the protocol, patients who did not complete one full dose were considered unevaluable and were replaced. Two patients randomized to Arm A, experienced an infusion reaction shortly after initiation of drug and did not complete the first dose and withdrew from the study. The event of infusion reaction resolved on the same day in both patients. Subsequently one patient recovered from COVID-19 in approximately 2 weeks and was discharged from the hospital. The second patient developed further complications of COVID-19 related ARDS and died 9 days after discontinuation and the event was deemed not related to the study drug.

All the infusion reactions ( 5 events) were considered related to study medication and resolved within a few hours with symptomatic management. These infusion reactions occurred when they were given over 2 hours. However, the reaction abated when the infusion was given over 5-6 hours.

No notable differences were seen between the arms in vital parameters and clinical laboratory (hematology and biochemistry) evaluations except lymphocyte count decrease, which was seen in $11(50 \%)$ patients in Arm A and $2(20 \%)$ patients in Arm B. The events in Arm A, although severe in nature, were transient, without any clinical consequences, and considered to be related to the study drug. The events can be attributed to the mechanism of action of the drug and expected in keeping with the known safety profile of the drug. 


\section{Discussion}

Progression of COVID-19 is associated with systemic hyperinflammation and elevation of inflammatory markers. As a consequence of this exaggerated immune response, there is a proinflammatory cytokine release syndrome, which is associated with high mortality in COVID-19 patients [26]. In patients in intensive care, who are critically ill (require ventilation) and seriously ill (require oxygen support), there is an increased concentration of IL-2, IL-7, IL-10, GM-CSF, IP10, MCP1, MIP1a and TNF-a [5]. This inflammatory pathophysiology of COVID-19 has encouraged research into the use of immunomodulating treatments, such as Itolizumab, in moderate to severe cases of COVID-19, which was approved seven years ago for use in psoriasis in India and has also been used in rheumatoid arthritis [27-29]. Further, the mechanism of action of Itolizumab ensures immunomodulating effect by acting upstream in the Th1 and Th17 pathways, thus providing additional benefits over other similar agents [30,31].

Building on the experience of using Itolizumab, its documented safety profile, and its mechanism of action, we undertook the current study to explore its potential to prevent cytokine release syndrome and reduce mortality in moderate to severe ARDS in COVID-19 patients. The current effort provides encouraging results, particularly with respect to mortality noted at the end of 30 days follow-up, and there is a need to replicate these findings either through additional, larger clinical trials or post-marketing surveillance studies.

With the global caseload of COVID-19 edging past 60 million, and the death tally having crossed a million, it is imperative to explore therapeutic alternatives which can not only prevent progression to severe disease, but also reduce mortality and morbidity before clinical response capacities are overwhelmed [1,32]. We identified a mortality benefit in the current study and 
interpret this cautiously considering the small sample size and usual limitations of undertaking an open label study, which has been conducted within the restrictions imposed by an ongoing pandemic [33]. We further acknowledge that the open-label design is also known to yield slightly larger estimates of effect size, to ameliorate which blinded, large clinical trials need to be conducted [34]. However, what is encouraging is that in addition to the mortality benefit, the current effort also identified favorable outcomes related to improved lung functions, biomarker profile and clinical resolution, especially with respect to respiratory/ventilatory support requirements. This constellation of clinical and laboratory findings supporting the beneficial effect of Itolizumab, which are likely to be internally valid for the given patient set, warrants deeper investigation to ensure generalizability and external validity of the results. The recent emergency use authorization accorded to Itolizumab for use in COVID-19 patients in India and Cuba, provides a window of opportunity to conduct a larger, global, phase 3 study and undertake post-marketing surveillance to explore the utility and impact of Itolizumab in COVID-19 cases with cytokine release syndrome.

The role of systemic vasculitis and cytokine mediated coagulation disorders have been recognized as significant factors for multi organ failure in patients with severe COVID-19 complications [35]. In patients with respiratory distress, levels of organ dysfunction markers such as D-dimer and lactate dehydrogenase (LDH) and surrogate markers of inflammation or cellular damage, such as ferritin and CRP, need to be closely monitored as they are considered as markers for potential progression to critical illness [36-38]. Elevated LDH levels indicate acute inflammation and have been associated with a 6-fold increase in the odds of progressing to severe COVID-19 and a 16fold increase in odds of dying from COVID-19 [39]. D-dimer levels indicate coagulopathy and higher values have been shown to be associated with poorer clinical outcomes [40,41]. Serum 
ferritin levels indicate RBC damage and have been identified to be independently associated with the development of severe COVID-19 [42]. Plasma CRP levels have also been associated with CT confirmed moderate to severe pneumonia in COVID-19 patients [43]. Encouraging trends were noted for all these biomarkers in Arm A patients, who received Itolizumab in addition to best standard of care. A consistent reduction in D-dimer and LDH levels were seen in Arm A unlike in Arm B where no pattern was observed. The mean change in ferritin from baseline was higher in Arm A at all timepoints. Further, decreasing levels of these markers was accompanied by clinical improvement in patients receiving Itolizumab.

A four-fold decrease was seen in IL-6 levels in Arm A after the administration of Itolizumab $(p=0.0269)$ while a $30 \%$ increase was observed in Arm B. Our findings are also in agreement with the preliminary findings from a small study from Cuba, where reduction in IL-6 levels was seen in COVID-19 patients treated with Itolizumab [44]. TNF- $\alpha$ also followed a similar trend (fourfold decrease) as IL6 in Arm A after administration of Itolizumab ( $p=0.025)$. In contrast, a threefold increase in TNF- $\alpha$ was seen in Arm B.

A decrease in lymphocyte count has been observed in COVID-19 patients [45]. Absolute lymphocyte count is considered as an important prognostic marker in COVID-19 infection [46]. In Arm A, a transient reduction in ALC was seen by Day 7, which was considered related to the study drug. However, the levels increased from Day 7 to Day 30 and was comparable to Arm B, and this did not have any adverse clinical outcomes in the patients.

A total of five serious TEAEs were reported in the study of which 3 deaths were reported in Arm B. Of the two serious TEAEs reported in Arm A, one (pericardial effusion) was related to underlying comorbidity (hypothyroidism) and was unrelated to the drug. The other was 
anaphylaxis due to infusion reaction, which is a known adverse effect of Itolizumab. The reported anaphylactic reaction was due to the shorter duration of infusion ( 2 hours). Other than the serious case of infusion reaction, non-serious treatment related infusion reactions were reported which abated with the extension of infusion period to 5-6 hours. The TEAEs such as infusion reactions and related events reported in the study were those expected for a monoclonal antibody (in treatment of psoriasis with the study drug, $10-15 \%$ of patients experienced infusion related reaction) [20]. The other treatment related AE was lymphocyte count decrease which was transient, and the patients recovered. In general, immunomodulatory drugs are expected to increase the risk of infection by acting on the immune system. However, in this study only one case of unrelated infection was reported in Arm A. These results are in line with the earlier finding with Itolizumab $[17,19,22,29,47]$.

Considering the paucity of clinical therapeutic alternatives for COVID-19, the current effort highlights Itolizumab as a promising prospect deserving further study. Several 'repurposed', 'emergency use' or 'off-label' drugs are being considered as treatment alternatives for management of cases in the earlier phase of the disease, when interfering with viral replication may provide clinical benefits. Hydroxychloroquine has been shown to have limited clinical effectiveness [48-54], and Remdesivir [55,56] Favipiravir [57,58] and convalescent plasma [5961] remain under investigation. If the patient enters the mechanical ventilation phase or when the patient's condition is deteriorating despite oxygen administration, corticosteroids like methyl prednisolone and dexamethasone can be administered to prevent inflammation and further reduce mortality $[35,62]$. Other interventions like heparin to prevent blood clots and thrombogenic response, antibiotics such as azithromycin and ivermectin to reduce infections continue to be used in mild to moderate cases of COVID-19. 
Immunomodulatory drugs find use in COVID-19 when the inflammatory cascades are starting to get activated. Tocilizumab, an IL-6 inhibitor, used in rheumatoid arthritis, has been repurposed for use in COVID-19, and has also received emergency use authorization in India. However, it remains limited by the fact that it blocks only IL-6, has no T-cell mediated immunomodulation, and has a short duration of action due to its downstream point of action [30,63-68]. Itolizumab has a broad immunological window being a CD6 inhibitor and is an option in the treatment of cytokine release syndrome in COVID-19 patients.

\section{Conclusion}

The current investigation highlights the potential of Itolizumab as a promising, safe and effective immunomodulatory therapy for COVID-19 patients with cytokine release syndrome, as it efficiently controls immune hyperactivation, resulting in reduction in morbidity and mortality from moderate to severe COVID-19. 


\section{Acknowledgements}

Editorial assistance was provided by Shivani Mittra, $\mathrm{PhD}$ and Ubhayabharathi Gurunath, M.Sc (Biocon Biologicals Ltd.).

Clinical support was provided by Arpitkumar Prajapati, M.D., Radhika A, M.D., and Sarika S Deodhar, M.D. (Biocon Biologicals Ltd).

Trial operation support was provided by Anirudh Sahoo, M.Pharm (Biocon Biologicals Ltd).

Sandeep N. Athalye, as the guarantor of this work, takes full responsibility for the work as a whole, including the study design, access to data, and the decision to submit and publish the manuscript.

\section{Funding}

The study was funded by Biocon Biologics India Limited and the funders did not have any role in patient recruitment and management.

\section{Disclosures}

Suresh Kumar, Rosemarie de Souza, Milind Nadkar, Randeep Guleria and Anjan Trikha report no competing interests. Subramanian Loganathan and Sandeep N. Athalye are employees of Biocon Biologics Ltd. and holds stocks in Biocon. Shashank R. Joshi has received Speaker/Advisory/Research Grants from Abbott, Astra, Biocon, Boehringer Ingelheim, Eli Lilly, Franco Indian, Glenmark, Lupin, Marico, MSD, Novartis, Novo Nordisk, Roche, Sanofi, Serdia and Zydus. Ashwani Marwah and Sivakumar Vaidyanathan are employees of Biocon Biologics Ltd. The authors have no other relevant affiliations or financial involvement with any organization or entity with a financial interest in or financial conflict with the subject matter or materials discussed in the manuscript apart from those disclosed. 


\section{Authorship Statement}

All authors were involved in the design of the clinical study, analyzed and interpreted the study data and results. All authors participated in the preparation and review of the manuscript. All authors read and approved the final version of the manuscript. 


\section{References}

1. Johns Hopkins CSSE. Coronavirus (COVID-19) Global Cases: Center for Systems Science and Engineering, Johns Hopkins University. 2020. Available: https://coronavirus.jhu.edu/map.html

2. Chatterjee P, Nagi N, Agarwal A, Das B, Banerjee S, Sarkar S, et al. The 2019 novel coronavirus disease (COVID-19) pandemic: A review of the current evidence. Indian J Med Res. 2020. doi:10.4103/ijmr.IJMR_519_20

3. Romagnoli S, Peris A, De Gaudio AR, Geppetti P. SARS-CoV-2 and COVID-19: From the Bench to the Bedside. Physiological Reviews. 2020;100: 1455-1466. doi:10.1152/physrev.00020.2020

4. Siddiqi HK, Mehra MR. COVID-19 illness in native and immunosuppressed states: A clinical-therapeutic staging proposal. J Heart Lung Transplant. 2020;39: 405-407. doi:10.1016/j.healun.2020.03.012

5. Tay MZ, Poh CM, Rénia L, MacAry PA, Ng LFP. The trinity of COVID-19: immunity, inflammation and intervention. Nat Rev Immunol. 2020;20: 363-374. doi:10.1038/s41577020-0311-8

6. Costela-Ruiz VJ, Illescas-Montes R, Puerta-Puerta JM, Ruiz C, Melguizo-Rodríguez L. SARS-CoV-2 infection: The role of cytokines in COVID-19 disease. Cytokine Growth Factor Rev. 2020 [cited 5 Aug 2020]. doi:10.1016/j.cytogfr.2020.06.001

7. Xu Z, Shi L, Wang Y, Zhang J, Huang L, Zhang C, et al. Pathological findings of COVID19 associated with acute respiratory distress syndrome. Lancet Respir Med. 2020;8: 420422. doi:10.1016/S2213-2600(20)30076-X 
8. Qin C, Zhou L, Hu Z, Zhang S, Yang S, Tao Y, et al. Dysregulation of Immune Response in Patients With Coronavirus 2019 (COVID-19) in Wuhan, China. Clin Infect Dis. 2020;71: 762-768. doi:10.1093/cid/ciaa248

9. Fu L, Wang B, Yuan T, Chen X, Ao Y, Fitzpatrick T, et al. Clinical characteristics of coronavirus disease 2019 (COVID-19) in China: A systematic review and meta-analysis. J Infect. 2020;80: 656-665. doi:10.1016/j.jinf.2020.03.041

10. Dogra S, D S, Rajagopalan M. Anti-CD6 mAbs for the treatment of psoriasis. Expert Opin Biol Ther. 2020; 1-7. doi:10.1080/14712598.2020.1776254

11. Arlati S. Shock States in Acute Care Surgery. 1st ed. In: Aseni P, Carlis LD, Mazzola A, Grande AM, editors. Operative Techniques and Recent Advances in Acute Care and Emergency Surgery. 1st ed. Springer International Publishing; 2019. p. 800. doi:10.1007/978-3-319-95114-0

12. McGee MC, August A, Huang W. BTK/ITK dual inhibitors: Modulating immunopathology and lymphopenia for COVID-19 therapy. J Leukoc Biol. 2020 [cited 2 Aug 2020]. doi:10.1002/JLB.5COVR0620-306R

13. Kaye AG, Siegel R. The Efficacy of IL-6 Inhibitor Tocilizumab in Reducing Severe COVID19 Mortality: A Systematic Review. medRxiv. 2020; 2020.07.10.20150938. doi:10.1101/2020.07.10.20150938

14. Regeneron and Sanofi Provide Update on U.S. Phase 2/3 Adaptive-Designed Trial of Kevzara ${ }^{\circledR}$ (sarilumab) in Hospitalized COVID-19 Patients | Regeneron Pharmaceuticals Inc. [cited 2 Aug 2020]. Available: https://investor.regeneron.com/news-releases/news-releasedetails/regeneron-and-sanofi-provide-update-us-phase-23-adaptive/ 
15. Garcia Santana CA, Tung JW, Gulnik S. Human treg cells are characterized by low/negative CD6 expression. Cytometry A. 2014;85: 901-908. doi:10.1002/cyto.a.22513

16. Pontali E, Volpi S, Antonucci G, Castellaneta M, Buzzi D, Tricerri F, et al. Safety and efficacy of early high-dose IV anakinra in severe COVID-19 lung disease. J Allergy Clin Immunol. 2020;146: 213-215. doi:10.1016/j.jaci.2020.05.002

17. Bughani U, Saha A, Kuriakose A, Nair R, Sadashivarao RB, Venkataraman R, et al. T cell activation and differentiation is modulated by a CD6 domain 1 antibody Itolizumab. PLoS ONE. 2017;12: e0180088. doi:10.1371/journal.pone.0180088

18. Nair P, Melarkode R, Rajkumar D, Montero E. CD6 synergistic co-stimulation promoting proinflammatory response is modulated without interfering with the activated leucocyte cell adhesion molecule interaction. Clin Exp Immunol. 2010;162: 116-130. doi:10.1111/j.13652249.2010.04235.x

19. Menon R, David BG. Itolizumab - a humanized anti-CD6 monoclonal antibody with a better side effects profile for the treatment of psoriasis. Clin Cosmet Investig Dermatol. 2015;8: 215-222. doi:10.2147/CCID.S47784

20. Krupashankar DS, Dogra S, Kura M, Saraswat A, Budamakuntla L, Sumathy TK, et al. Efficacy and safety of itolizumab, a novel anti-CD6 monoclonal antibody, in patients with moderate to severe chronic plaque psoriasis: results of a double-blind, randomized, placebocontrolled, phase-III study. J Am Acad Dermatol. 2014;71: 484-492. doi:10.1016/j.jaad.2014.01.897

21. Björklund ÅK, Forkel M, Picelli S, Konya V, Theorell J, Friberg D, et al. The heterogeneity of human $\mathrm{CD} 127(+)$ innate lymphoid cells revealed by single-cell RNA sequencing. Nat Immunol. 2016;17: 451-460. doi:10.1038/ni.3368 
22. Braun M, Müller B, ter Meer D, Raffegerst S, Simm B, Wilde S, et al. The CD6 scavenger receptor is differentially expressed on a CD56 natural killer cell subpopulation and contributes to natural killer-derived cytokine and chemokine secretion. J Innate Immun. 2011;3: 420-434. doi:10.1159/000322720

23. Singh V. Clinical Outcome of a Novel Anti-CD6 Biologic Itolizumab in Patients of Psoriasis with Comorbid Conditions. Dermatol Res Pract. 2016;2016: 1316326. doi:10.1155/2016/1316326

24. Pai G, Pai AH. Itolizumab - A New Biologic for Management of Psoriasis and Psoriatic Arthritis. Case Rep Dermatol. 2017;9: 141-145. doi:10.1159/000475519

25. de Wit J, Souwer Y, van Beelen AJ, de Groot R, Muller FJM, Klaasse Bos H, et al. CD5 costimulation induces stable Th17 development by promoting IL-23R expression and sustained STAT3 activation. Blood. 2011;118: 6107-6114. doi:10.1182/blood-2011-05352682

26. Mehta P, McAuley DF, Brown M, Sanchez E, Tattersall RS, Manson JJ. COVID-19: consider cytokine storm syndromes and immunosuppression. The Lancet. 2020;395: 1033-1034. doi:10.1016/S0140-6736(20)30628-0

27. Chopra A, Chandrashekara S, Iyer R, Rajasekhar L, Shetty N, Veeravalli SM, et al. Itolizumab in combination with methotrexate modulates active rheumatoid arthritis: safety and efficacy from a phase 2, randomized, open-label, parallel-group, dose-ranging study. Clin Rheumatol. 2016;35: 1059-1064. doi:10.1007/s10067-015-2988-9

28. Rodríguez PC, Prada DM, Moreno E, Aira LE, Molinero C, López AM, et al. The anti-CD6 antibody itolizumab provides clinical benefit without lymphopenia in rheumatoid arthritis 
patients: results from a 6-month, open-label Phase I clinical trial. Clin Exp Immunol. 2018;191: 229-239. doi:10.1111/cei.13061

29. Dogra S, D S K, Budamakuntla L, Srinivas CR, Khopkar U, Gupta S, et al. Long-term efficacy and safety of itolizumab in patients with moderate-to-severe chronic plaque psoriasis: A double-blind, randomized-withdrawal, placebo-controlled study. J Am Acad Dermatol. 2015;73: 331-333.e1. doi:10.1016/j.jaad.2015.03.040

30. Loganathan S, Athalye SN, Joshi SR. Itolizumab, an anti-CD6 monoclonal antibody, as a potential treatment for COVID-19 complications. Expert Opinion on Biological Therapy. 2020;0: 1-7. doi:10.1080/14712598.2020.1798399

31. Budamakuntla L, Madaiah M, Sarvajnamurthy S, Kapanigowda S. Itolizumab provides sustained remission in plaque psoriasis: a 5-year follow-up experience. Clinical and Experimental Dermatology. 2015;40: 152-155. doi:10.1111/ced.12509

32. Agarwal A, Nagi N, Chatterjee P, Sarkar S, Mourya D, Sahay R, et al. Guidance for building a dedicated health facility to contain the spread of the 2019 novel coronavirus outbreak. Indian J Med Res. 2020;Epub ahead of print. doi:10.4103/ijmr.IJMR_518_20

33. Schulz KF, Grimes DA. Blinding in randomised trials: hiding who got what. Lancet. 2002;359: 696-700. doi:10.1016/S0140-6736(02)07816-9

34. Schulz KF, Chalmers I, Hayes RJ, Altman DG. Empirical evidence of bias. Dimensions of methodological quality associated with estimates of treatment effects in controlled trials. JAMA. 1995;273: 408-412. doi:10.1001/jama.273.5.408

35. Fadel R, Morrison A, Vahia A, Smith ZR, Chaudhry Z, Bhargava P, et al. Early Short Course Corticosteroids in Hospitalized Patients with COVID-19. medRxiv. 2020; 2020.05.04.20074609. doi:10.1101/2020.05.04.20074609 
36. Henry BM, de Oliveira MHS, Benoit S, Plebani M, Lippi G. Hematologic, biochemical and immune biomarker abnormalities associated with severe illness and mortality in coronavirus disease 2019 (COVID-19): a meta-analysis. Clin Chem Lab Med. 2020;58: 1021-1028. doi:10.1515/cclm-2020-0369

37. Zhang C, Wu Z, Li J-W, Zhao H, Wang G-Q. Cytokine release syndrome in severe COVID19: interleukin-6 receptor antagonist tocilizumab may be the key to reduce mortality. International Journal of Antimicrobial Agents. 2020;55: 105954. doi:10.1016/j.ijantimicag.2020.105954

38. Tang N, Li D, Wang X, Sun Z. Abnormal coagulation parameters are associated with poor prognosis in patients with novel coronavirus pneumonia. Journal of Thrombosis and Haemostasis. 2020;18: 844-847. doi:10.1111/jth.14768

39. Henry BM, Aggarwal G, Wong J, Benoit S, Vikse J, Plebani M, et al. Lactate dehydrogenase levels predict coronavirus disease 2019 (COVID-19) severity and mortality: A pooled analysis. Am J Emerg Med. 2020;38: 1722-1726. doi:10.1016/j.ajem.2020.05.073

40. Vidali S, Morosetti D, Cossu E, Luisi MLE, Pancani S, Semeraro V, et al. D-dimer as an indicator of prognosis in SARS-CoV-2 infection: a systematic review. ERJ Open Res. 2020;6. doi:10.1183/23120541.00260-2020

41. Tang N, Bai H, Chen X, Gong J, Li D, Sun Z. Anticoagulant treatment is associated with decreased mortality in severe coronavirus disease 2019 patients with coagulopathy. J Thromb Haemost. 2020. doi:10.1111/jth. 14817

42. Lin Z, Long F, Yang Y, Chen X, Xu L, Yang M. Serum ferritin as an independent risk factor for severity in COVID-19 patients. J Infect. 2020 [cited 6 Aug 2020]. doi:10.1016/j.jinf.2020.06.053 
43. Chen W, Zheng KI, Liu S, Yan Z, Xu C, Qiao Z. Plasma CRP level is positively associated with the severity of COVID-19. Annals of Clinical Microbiology and Antimicrobials. 2020;19: 18. doi:10.1186/s12941-020-00362-2

44. Saavedra D, Añé-Kourí AL, Sánchez N, Filgueira LM, Betancourt J, Herrera C, et al. An Anti-CD6 Monoclonal Antibody (Itolizumab) Reduces Circulating IL-6 in Severe Covid-19 Elderly Patients. Research Square PREPRINT. 2020 [cited 2 Aug 2020]. doi:10.21203/rs.3.rs-32335/v1

45. Tavakolpour S, Rakhshandehroo T, Wei EX, Rashidian M. Lymphopenia during the COVID19 infection: What it shows and what can be learned. Immunol Lett. 2020;225: 31-32. doi:10.1016/j.imlet.2020.06.013

46. Wagner J, DuPont A, Larson S, Cash B, Farooq A. Absolute lymphocyte count is a prognostic marker in Covid-19: A retrospective cohort review. International Journal of Laboratory Hematology. n/a. doi:10.1111/ijlh.13288

47. Parthasaradhi A. Safety and Efficacy of Itolizumab in the Treatment of Psoriasis: A Case Series of 20 Patients. J Clin Diagn Res. 2016;10: WD01-WD03. doi:10.7860/JCDR/2016/21040.8848

48. COVID-19 drugs trial rolled out across UK homes and communities | University of Oxford. [cited 2 Aug 2020]. Available: https://www.ox.ac.uk/news/2020-05-12-covid-19-drugs-trialrolled-out-across-uk-homes-and-communities

49. Chatterjee P, Anand T, Singh K, Rasaily R, Singh R, Das S, et al. Healthcare workers \& SARS-CoV-2 infection in India: A case-control investigation in the time of COVID-19. Indian J Med Res. 2020;0: 0. doi:10.4103/ijmr.IJMR_2234_20 
50. NIH begins clinical trial of hydroxychloroquine and azithromycin to treat COVID-19. In: National Institutes of Health (NIH) [Internet]. 14 May 2020 [cited 2 Aug 2020]. Available: https://www.nih.gov/news-events/news-releases/nih-begins-clinical-trialhydroxychloroquine-azithromycin-treat-covid-19

51. Wright JK, Tan DHS, Walmsley SL, Hulme J, O’Connor E, Snider C, et al. Protecting Frontline Health Care Workers from COVID-19 with Hydroxychloroquine Pre-exposure Prophylaxis: A structured summary of a study protocol for a randomised placebo-controlled multisite trial in Toronto, Canada. Trials. 2020;21: 647. doi:10.1186/s13063-020-04577-8

52. Mahase E. Hydroxychloroquine for covid-19: the end of the line? BMJ. 2020;369: m2378. doi:10.1136/bmj.m2378

53. Skipper CP, Pastick KA, Engen NW, Bangdiwala AS, Abassi M, Lofgren SM, et al. Hydroxychloroquine in Nonhospitalized Adults With Early COVID-19: A Randomized Trial. Ann Intern Med. 2020. doi:10.7326/M20-4207

54. Boulware DR, Pullen MF, Bangdiwala AS, Pastick KA, Lofgren SM, Okafor EC, et al. A Randomized Trial of Hydroxychloroquine as Postexposure Prophylaxis for Covid-19. N Engl J Med. 2020. doi:10.1056/NEJMoa2016638

55. Goldman JD, Lye DCB, Hui DS, Marks KM, Bruno R, Montejano R, et al. Remdesivir for 5 or 10 Days in Patients with Severe Covid-19. N Engl J Med. 2020. doi:10.1056/NEJMoa2015301

56. Beigel JH, Tomashek KM, Dodd LE, Mehta AK, Zingman BS, Kalil AC, et al. Remdesivir for the Treatment of Covid-19 - Preliminary Report. N Engl J Med. 2020. doi:10.1056/NEJMoa2007764 
57. Glenmark Pharmaceuticals. Glenmark to Commence New Phase 3 Clinical Trial on Combination of Two Anti-viral Drugs Favipiravir and Umifenovir in Hospitalized Patients of Moderate COVID-19 in India. In: PR Newswire [Internet]. [cited 2 Aug 2020]. Available: https://www.prnewswire.com/in/news-releases/glenmark-to-commence-new-phase-3clinical-trial-on-combination-of-two-anti-viral-drugs-favipiravir-and-umifenovir-inhospitalized-patients-of-moderate-covid-19-in-india-836904730.html

58. Chen C, Zhang Y, Huang J, Yin P, Cheng Z, Wu J, et al. Favipiravir versus Arbidol for COVID-19: A Randomized Clinical Trial. medRxiv. 2020; 2020.03.17.20037432. doi:10.1101/2020.03.17.20037432

59. Gharbharan A, Jordans CCE, GeurtsvanKessel C, Hollander JG den, Karim F, Mollema FPN, et al. Convalescent Plasma for COVID-19. A randomized clinical trial. medRxiv. 2020; 2020.07.01.20139857. doi:10.1101/2020.07.01.20139857

60. Joyner MJ, Klassen SA, Senefeld J, Johnson PW, Carter RE, Wiggins CC, et al. Evidence favouring the efficacy of convalescent plasma for COVID-19 therapy. medRxiv. 2020; 2020.07.29.20162917. doi:10.1101/2020.07.29.20162917

61. Indian Council of Medical Research. A Phase II, Open Label, Randomized Controlled Trial to Assess the Safety and Efficacy of Convalescent Plasma to Limit COVID-19 Associated Complications in Moderate Disease. CDSCO; Available: https://cdsco.gov.in/opencms/resources/UploadCDSCOWeb/2018/UploadPublic_NoticesFil es/amended\%20Clinical\%20Trial\%20protocol\%20version $\% 201.4 \% 20 \% 20$ by $\% 20$ ICMR $\%$ 20dated\%202020.pdf

62. Low-cost dexamethasone reduces death by up to one third in hospitalised patients with severe respiratory complications of COVID-19 | University of Oxford. [cited 2 Aug 2020]. 
Available: https://www.ox.ac.uk/news/2020-06-16-low-cost-dexamethasone-reduces-deathone-third-hospitalised-patients-severe

63. Jain S, Sharma SK. Rational use of tocilizumab in COVID-19. Ann Rheum Dis. 2020. doi:10.1136/annrheumdis-2020-218519

64. Cascella M, Mauro I, De Blasio E, Crispo A, Del Gaudio A, Bimonte S, et al. Rapid and Impressive Response to a Combined Treatment with Single-Dose Tocilizumab and NIV in a Patient with COVID-19 Pneumonia/ARDS. Medicina (Kaunas). 2020;56. doi:10.3390/medicina56080377

65. Keske Ş, Tekin S, Sait B, İrkören P, Kapmaz M, Çimen C, et al. Appropriate use of Tocilizumab in COVID-19 Infection. Int J Infect Dis. 2020. doi:10.1016/j.ijid.2020.07.036

66. Patel A, Shah K, Dharsandiya M, Patel K, Patel T, Patel M, et al. Safety and efficacy of tocilizumab in the treatment of severe acute respiratory syndrome coronavirus- 2 pneumonia: A retrospective cohort study. Indian J Med Microbiol. 2020;38: 117-123. doi:10.4103/ijmm.IJMM_20_298

67. Ip A, Berry DA, Hansen E, Goy AH, Pecora AL, Sinclaire BA, et al. Hydroxychloroquine and Tocilizumab Therapy in COVID-19 Patients - An Observational Study. medRxiv. 2020; 2020.05.21.20109207. doi:10.1101/2020.05.21.20109207

68. Somers EC, Eschenauer GA, Troost JP, Golob JL, Gandhi TN, Wang L, et al. Tocilizumab for treatment of mechanically ventilated patients with COVID-19. Clin Infect Dis. [cited 2 Aug 2020]. doi:10.1093/cid/ciaa954 